book, will probably say “Let's just try it !” Pierre Chirac is a public-health pharmacist with the Médecins Sans Frontières Access to Essential Medicines Campaign, 2 rue Chaligny, 75012 Paris, France.

\section{The other evolutionist}

The Heretic in Darwin's Court: The Life of Alfred Russel Wallace

by Ross Slotten

Columbia University Press: 2004. 648 pp.

$\$ 39.50, £ 26.50$

\section{An Elusive Victorian: The}

Evolution of Alfred Russel Wallace

by Martin Fichman

Chicago University Press: 2004. 416 pp.

$\$ 40, £ 28$

\section{George Beccaloni}

Lying ill with fever on the remote Molluccan island of Halmahera in February 1858, the English naturalist Alfred Russel Wallace puzzled over the phenomenon of 'species transmutation' - a subject that had rarely been absent from his thoughts for the past 13 years. Three years earlier he had published an important but largely unnoticed paper on this topic, now known as evolution, in which he strongly argued that organisms must have evolved from earlier forms. But the mechanism of this process had so far eluded him — as it had (virtually) everyone else.

Suddenly, a flash of insight led him to the idea of natural selection as the mechanism driving evolutionary change. Once he had recovered enough strength, he fleshed out his ideas in an essay entitled "On the Tendency of Varieties to Depart Indefinitely from the Original Type". Knowing that his occasional correspondent Charles Darwin was also keenly interested in the 'species problem', he sent the essay to him on the next mail boat that departed from the neighbouring island of Ternate. Unknown to Wallace, Darwin had in fact discovered natural selection some 20 years earlier and, urged on by the geologist Charles Lyell, he was slowly writing a huge tome in which he planned to present his 'heretical' theory to the world.

The events that unfolded following Darwin's receipt of Wallace's essay have become legendary. Realizing that Wallace had independently reached the same conclusion as himself, Darwin was thrown into a state of confusion and despair. He wrote to Lyell: "Your words have come true with a vengeance ... all my originality will be smashed." Lyell contacted another of Darwin's influential friends, the botanist Joseph Hooker, and together they sought to remedy the awkward situation as best they could.

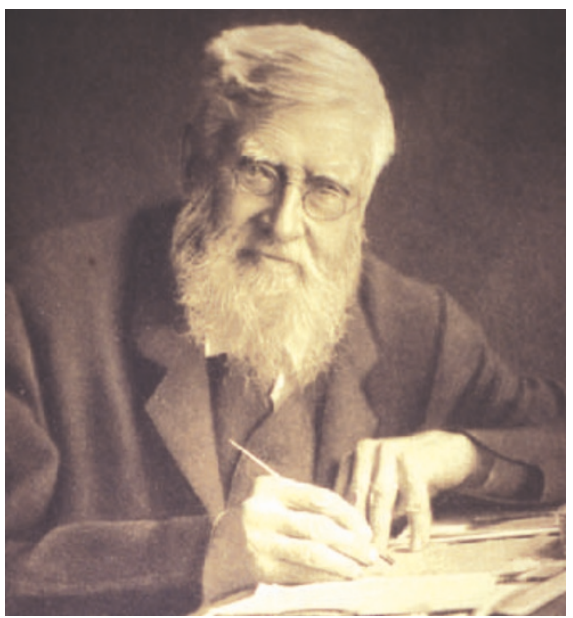

Alfred Russel Wallace wrote some 700 articles and 20 books on a wide range of subjects.

Without first asking Wallace's permission, they arranged for his essay to be read at a meeting of the Linnean Society in July 1858 , along with an abstract of an unpublished manuscript on natural selection that Darwin had written in 1844, and an abstract of a letter outlining the concept of descent with modification that Darwin had sent to the American botanist Asa Gray the year before. By arranging these texts in the order in which they had been written, Lyell and Hooker secured Darwin's priority, and when they were published a month later, Darwin's name naturally appeared as first author of what became the first publication to explicitly propose the theory of evolution by natural selection. This, together with the fact that Darwin's Origin of Species (an abstract of his "big book") was printed only a year later, are two of the reasons why Wallace often receives little or no recognition for the discovery.

The Heretic in Darwin's Court by Ross Slotten and An Elusive Victorian by Martin Fichman are the latest in a recent spate of books that examine Wallace's fascinating life and often controversial work. Slotten's book is a conventional, chronologically arranged biography, whereas Fichman's aims to provide "a contextualist and analytical study of Wallace's major intellectual and cultural views and activities".

Slotten's book is the most detailed study of its kind published to date and provides a vivid account of Wallace's rich 90-year life. It covers his early impecunious years at school in Hertford (he left school aged 13) and his training as a land surveyor; his four years collecting biological specimens in the Amazon basin (many of which were destroyed when his ship sank on the way back to Britain); his eight years collecting in Southeast Asia (he sent back 126,000 biological specimens, including 1,000 species new to science); and his years in England, during which he wrote some 700 articles and 20 books on an eclectic range of subjects and made a prodigious number of seminal contributions to the fields of biology, geography, geology and anthropology, among others. Slotten attempts to produce a "three-dimensional portrait of a man whose forays into spiritualism, socialism, antivaccinationism, and other unorthodox 'isms' have been caricatured, overanalyzed, or ignored by specialists in the academic world". However, like most previous biographers, Slotten seems perplexed by some of Wallace's seemingly crackpot beliefs, and although he discusses them at length, he makes little attempt to analyse them in depth.

Fichman, in contrast, tries to do just that and adopts a thematic approach to scrutinize each of Wallace's major interests in turn. $\mathrm{He}$ argues that Wallace sought to integrate his beliefs into a single internally consistent world view, which he calls Wallace's "teleological evolutionary cosmology", and he maintains that many of Wallace's putative unorthodoxies are in fact artefacts of historiography. From a modern perspective, it may seem inappropriate for an 'objective' scientist to espouse beliefs such as spiritualism, as Wallace did, but in the late nineteenth century and the early part of the twentieth it was entirely acceptable for scientists to do so.

Fichman's book is the more challenging read and is likely to appeal mainly to serious Wallace scholars. But to understand why a book like Fichman's is needed in the first place, anyone unfamiliar with Wallace's work should probably study a biography such as Slotten's.

George Beccaloni is an entomologist at the

Natural History Museum, Cromwell Road, South Kensington, London SW7 5BD, UK. He organized a project to restore Wallace's neglected grave.

\section{Cycles of life}

Nutrient Cycling and Limitation: Hawai'i as a Model System

by Peter Vitousek

Princeton University Press: 2004. 232 pp.

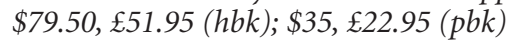

\section{David Schimel}

The regulation of growth by nutrient availability and the control of cycling of the elements through living communities are basic ideas in the field of ecology. Nutrient cycling, or biogeochemistry as it is known, is now a rich research field with a vast literature linked to disciplines as disparate as ecology, soil science and atmospheric science. It forms a bridge between the life and earth sciences, both of which are concerned with the cycling of elements but for vastly different reasons.

The ecological or process-oriented approach to nutrient cycling largely traces back to seminal work in New England in the 1960s and 1970s. In that oeuvre, Peter Vitousek's work for his doctoral thesis began 


\section{A world of learning}

The small publishing house Eichborn regrets that "whereas the Bible is sold off at any supermarket, Alexander von Humboldt's counter-theories to the holy writings are hard to find even in the largest of book shops". In the hope of correcting this, Eichborn is republishing three of the explorer-scientist's most important works.

Von Humboldt, born in 1769, remains one of Germany's most important intellectual figures. Deeply committed to Enlightenment principles, he was a collector of knowledge. He travelled extensively, learning the language of each country he visited. He was an internationalist, and persuaded Prussia's King Friedrich Wilhelm IV to inaugurate, in 1842, the Order Pour le mérite für Wissenschaften und Künste, the first such civilian society in war-torn Europe to recognize individual academic achievement across borders.

to place nutrient cycling in a mechanistic rather than a budgetary framework. The concept of the limitation of nutrients was central, defined as "occurring when the addition of an essential element increases the growth of individual organisms or populations, or increases the rate of a biological process" (F.S. Chapin etal. Am. Nat. 127,48-58; 1986). Nutrient limitation had long been known to foresters and agronomists as a spatially variable property but was usually treated as a static site characteristic. Following the publication of the nutrient-retention hypothesis by Vitousek and William Reiners (BioScience 25, 376-381; 1975), nutrient availability was viewed as an emergent property of an ecosystem, a dynamic property controlled by biological, hydrological and geological interactions.

I vividly remember Vitousek stating in a (probably beer-fuelled) conversation about research focus and scientific success that his focus was on "understanding nutrient limitation during succession". His work began by understanding the interactive controls over nutrient limitation after forest disturbance. In Nutrient Cycling and Limitation, Vitousek explores this theme on a grand canvas, basing it on his own work and that of a small army of students and collaborators.

The island of Hawaii is formed from lava flows of diverse and known ages spanning many millions of years. Ecosystems have developed on soils formed from these lava, drawing from a relatively common palette of species but under vastly different conditions of nutrient limitation, depending on the age of the soils. Vitousek reports on several decades of research using age gradients

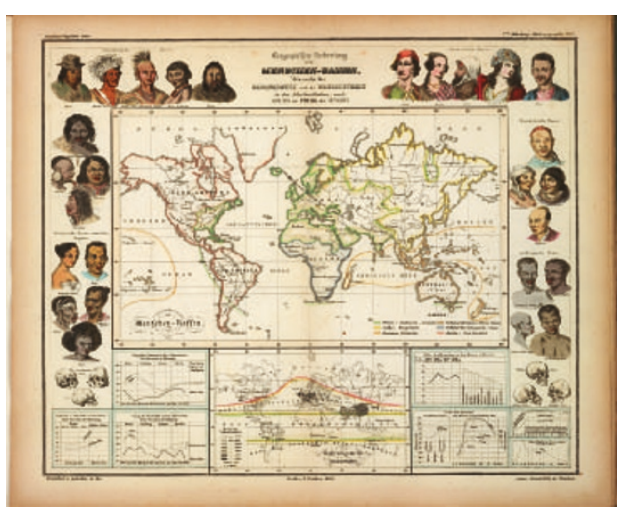

His massive tome Kosmos was an attempt to synthesize all the knowledge of the physical world, from thousands of different sources, including his own scientific travels. It was illustrated with maps like the one shown here, describing not only geography but also geology, biology and anthropology. Kosmos was a thirty-year labour of love, and von Humboldt was reportedly still adding to it on his dying day, aged 89. The work was a best seller in the nineteenth century, and was translated into many languages. But it faded from view in the twentieth century, and few Germans today have read the original words.

The publication of Kosmos marks the 200th anniversary of Humboldt's return from his five-year exploration of the Americas.

The two companion volumes are Ansichten der Natur (Views of Nature) and the sumptuously illustrated Ansichten der Kordilleren und Monumente der eingeborenen Völker Amerikas (Views of the Cordilleras and Monuments of the indigenous American Peoples), which has, in fact, never previously been published in German.

www.eichborn.de (along with climatic gradients and manipulation and natural disturbance within the geological template) aimed at understanding how nutrient limitation has evolved as the lava soils of Hawaii have aged over the past 5 million years or so.

He expands the concepts of nutrient cycling, inputs and losses on the ecosystem disturbance and recovery time scale (from 10 to 1,000 years) to geological time. Pro-

ratios reflecting these inputs over the ages.

While Nutrient Cycling and Limitation builds a strong bridge to the geological view of biogeochemistry, and to geological time scales, it also extends the biological paradigm. In geochemistry, organisms often appear as essentially passive transducers of physical forces into chemical dynamics. In this view, athough rates might differ in the presence or absence of organisms, the geophysical environment is viewed as shaping the system.

Vitousek's view of nature is richer by far. He shows how the biogeochemical characteristics of organisms can alter the trajectory of geochemical development, on multiple time scales. He views these organismal characteristics as being shaped by the organisms' deep evolutionary history. When organisms migrate to or invade Hawaii, the conflict between their evolutionary history and that of the island can create new biogeochemical conditions and complex responses. This leads to a contingent rather than an environmentally deterministic view of ecological dynamics, and is

cesses that on ecosystem time scales are either too slow to matter, or too episodic, come to dominate on geological time scales. Expanding the time scale expands the spatial scale as well: the parsimonious explanation for some aspects of Hawaiian geochemistry turns out to be the transport of nutrient-containing dust across the Pacific, a process that occurs at low instantaneous rates and during climatic episodes separated in geological time, but that is essential to budgets over millions of years. Today's Hawaiian ecosystem dynamics, though, are controlled partly by nutrient budgets and an important counterpart to the simpler views often espoused in biogeography.

This short review does not do justice to the range of topics addressed in Nutrient Cycling and Limitation, nor does it convey the depth of theoretical perspective couched in reams of hard-won experimental and observational data. This book will reward reading and rereading, and is an excellent introduction to biogeochemical ecology for those coming from other fields of science.

David Schimel is at the National Center for

Atmospheric Research, Boulder,

Colorado 80305, USA. 